\title{
Genetic Diversity and Structure in Japanese Populations of the Osprey (Pandion haliaetus), Based on mtDNA
}

\author{
Kazuya Nagai1,2*, Takayuki Sakakibara ${ }^{3,4}$, Atsuki Azuma1 \\ ${ }^{1}$ Faculty of Agriculture, Iwate University, Iwate, Japan \\ ${ }^{2}$ Research and Education Centre for Natural Sciences, Keio University, Kanagawa, Japan \\ ${ }^{3}$ Graduate School of Agriculture, Hokkaido University, Hokkaido, Japan \\ ${ }^{4}$ Civil Engineering \& Eco-technology Consultants Co., Ltd., Tokyo, Japan \\ Email: *nagai@iwate-u.ac.jp
}

How to cite this paper: Nagai, K., Sakakibara, T. and Azuma, A. (2021) Genetic Diversity and Structure in Japanese Populations of the Osprey (Pandion haliaetus), Based on mtDNA. Open Journal of Genetics, 11, 42-55.

https://doi.org/10.4236/ojgen.2021.113005

Received: August 16, 2021

Accepted: September 13, 2021

Published: September 16, 2021

Copyright $\odot 2021$ by author(s) and Scientific Research Publishing Inc. This work is licensed under the Creative Commons Attribution International License (CC BY 4.0).

http://creativecommons.org/licenses/by/4.0/

\begin{abstract}
Osprey is a type of bird of prey that lives almost all over the world. In Japan, it is designated as a near-threatened species because it has less than 1000 individuals. In recent years, it inhabits more inland than in coastal areas. In this study, we conducted a population genetic analysis focusing on what kind of genetic structure Japanese Osprey retains and whether there are differences between coastal and inland populations. We also performed genetic diversity assessments. We sequenced about $2.3 \mathrm{~kb}$ of mtDNA for 27 individuals in Japan, and phylogenetic analysis, network analysis, neutrality test and mismatch distribution analysis were performed. Eighteen haplotypes were detected in 27 individuals, indicating that genetic diversity was sufficiently high. Both unique and common haplotypes were detected between inland and coastal populations, suggesting gene flow between the two populations. Phylogenetic analysis results show no genetic differentiation in the Japanese Osprey population. From the results of network analysis, neutrality test and mismatch distribution analysis, it was inferred that the Japanese Osprey had a population expansion in the past. This study indicated that the dispersion of Japanese Osprey was random and there were no restrictions on the breeding area. The information presented here can be used towards implementing future conservation actions.
\end{abstract}

\section{Keywords}

Genetic Diversity, Osprey, MtDNA, Phylogeography, Cytochrome b, Control Region 


\section{Introduction}

The Osprey is a medium-sized bird of prey that is distributed all over the world. It is mainly a fish eater and inhabits coastal areas [1] [2] [3] [4]. The population in cold regions is a partially migratory bird that overwinters in warm regions [5].

From the results of molecular phylogenetic analysis using nuclei and mtDNA, it was found that unlike other birds of prey, it forms another family (Pandionidae) independently [6] [7]. The genus Pandion is composed of two species, $P$. cristatus (Eastern Osprey), which inhabits Indo-Pacific and Oceania, and P. haliaetus (Western Osprey; hereinafter referred to as Osprey), which inhabits other regions around the world [8] [9]. Also, Osprey is classified into 3 subspecies: $P$. h. haliaetus in the Palearctic from Europe, northwest Africa, and Asia north of the Himalayas, $P$. h. carolinensis in North America, P. h. ridgwayi in Caribbean Islands, these three subspecies have been found to be genetically distinct [10]. In addition, it has been suggested that the Osprey originated from the New World, then expanded its habitat westward into the Old World, and invaded Asia include Japan several times [10].

The population of ospreys in Japan in 2012 is thought to be less than 1000 individuals [11]. For this reason, Osprey is designated as Near Threatened, (NT) by the Japanese Ministry of the Environment's Red List and is protected [12]. One of the causes of the decline in Osprey populations is thought to be that water pollution has made it more difficult for them to feed [13]. In the U.S., pesticide contamination and the cutting down of nesting trees have been found to have drastically reduced the osprey population [14]. The other cause of the decline in Osprey populations is the decrease in pine forests where Ospreys nest [15]. Establishing nesting habitat is one of Osprey's conservation policies [16].

Birds of prey, including osprey, are ecosystem umbrella species, and the presence of birds of prey has been shown to be closely linked to ecosystem stability and biodiversity [17].

The low population size of this species raises concerns about reduced genetic diversity. Assessment of the genetic diversity of this species is an urgent task because it is essential to increase genetic diversity as well as population size in order to protect the species at risk. In recent years, the number of Osprey inhabitants has increased in Japan near dam lakes inland rather than coastal areas [18]. It is unclear why Osprey is expanding inland, but it is known that food resources depend on dam lake fish [19]. There is no clear difference in morphology or other characteristics between osprey inhabiting coastal areas and osprey inhabiting inland dam lakes. There is a difference in habitat, with the inland population feeding mainly on largemouth bass and crucian carp, while the coastal population feeds mainly on Belonidae and mackerel [20].

In this study, we aimed to assess whether genetic diversity of the current population of Osprey in Japan is high or low. Specifically, we elucidated the genetic structure of this population by conducting mitochondrial DNA (mtDNA) sequencing of feathers collected from fields or corpses. A comparative analysis of 
27 samples collected from eight locations was performed. To clarify if there are any restrictions on migration or breeding areas, we also investigated whether there is any gene flow between coastal and inland populations. Another purpose is to test the hypothesis of Monti et al. 2015. We examined the genetic structure of Osprey in Japan to determine if there have been multiple invasions of Japan.

Our results are expected to provide baseline information on the genetic diversity and structure of the Osprey, which may be used to implement strategies to protect breeding and nesting sites in Japan and to optimize efforts for conserving genetic diversity.

\section{Materials and Methods}

\subsection{Sampling}

A total of 27 feathers samples of Osprey used in the present study were collected from the field at eight locations in Japan (Table 1; Figure 1). Samples we picked up were collected from nest or from the ground within a $3-4 \mathrm{~m}$ radius from just under the nest, and one sample was collected from one nest to avoid duplication of the same individual. Or we got feather samples from corpses that were stored frozen or from museum specimen. All samples were obtained from Iwate, Aomori, Yamagata, Niigata, Chiba, Fukui, Fukuoka, and Okinawa in Japan between 2017 to 2020, and were sheltered from the sun immediately after collection and were frozen to avoid DNA degradation. All but two of the 14 samples from Iwate Prefecture were collected from nests near inland dam lakes. All samples from other regions were collected along the coast. Only those breeding near inland dam lakes were considered "Inland" and the rest as "Coastal". Since it is unclear which local populations are migratory, we did not distinguish between migratory and resident birds in other regions except Okinawa [13].

\subsection{DNA Extraction and PCR}

DNA was extracted from the feathers through the spin-column method (NucleoSpin Tissue Kit; MACHEREY-NAGEL, Düren, Germany). The feathers containing soft tissues were cut into small pieces using sterilized scissors, placed in $200 \mu \mathrm{L}$ of DNA extraction buffer and incubated overnight at $56^{\circ} \mathrm{C}$, resulting to an eluted final volume of $50 \mu \mathrm{L}$. A partial mtDNA fragment of Cytochrome b (cyt b) to the Control Region (CR) was amplified through polymerase chain reaction (PCR) using the following primers specifically designed for this study; Pah-cytb-F13621 (5'-CATTAGACCAAACAAATGGCC-3') and Pah-CR-R16035 (5'-TGGTGAAGGTTTGAGTCCTT-3'). The mtDNA control region has been widely applied to the population genetics of various animal species including birds because its mutation rate is approximately 2.8 - 5 times faster than other sequence segments [21] [22] [23] [24].

This amplification process was conducted using a reaction mixture of $20 \mu \mathrm{L}$ containing $1 \mu \mathrm{L}$ template DNA, $10 \mathrm{mM}$ deoxynucleotides (2.5 mM each), $5 \mathrm{nM}$ 
Table 1. Japanese sample list and detected haplotype ID.

\begin{tabular}{|c|c|c|c|c|}
\hline Sample ID & Location & Collection date & Inland or Coastal & Haplotype ID \\
\hline 1 & Iwate & 2018, August & Inland & 1 \\
\hline 2 & Iwate & 2018, July & Inland & 2 \\
\hline 3 & Iwate & 2018, July & Inland & 16 \\
\hline 5 & Iwate & 2018, July & Inland & 1 \\
\hline 6 & Iwate & 2017 July & Inland & 1 \\
\hline 7 & Iwate & 2018, July & Inland & 14 \\
\hline 9 & Iwate & 2018, May & Inland & 15 \\
\hline 10 & Iwate & 2018, July & Inland & 3 \\
\hline 11 & Iwate & 2018, July & Inland & 17 \\
\hline 14 & Yamagata & 2018, July & Coastal & 4 \\
\hline 15 & Niigata & 2018, July & Coastal & 14 \\
\hline 16 & Fukuoka & 2016, April & Coastal & 6 \\
\hline 21 & Iwate & 2019, July & Coastal & 5 \\
\hline 22 & Iwate & 2019, July & Coastal & 2 \\
\hline 23 & Iwate & 2019, July & Inland & 11 \\
\hline 24 & Iwate & 2019, July & Inland & 17 \\
\hline 25 & Iwate & 2019, July & Inland & 18 \\
\hline 26 & Okinawa & 2014, October & Coastal & 17 \\
\hline 27 & Okinawa & 2015 , October & Coastal & 10 \\
\hline 28 & Aomori & 2019, October & Coastal & 7 \\
\hline 29 & Fukuoka & 1990, January & Coastal & 12 \\
\hline 30 & Fukuoka & 2019, September & Coastal & 13 \\
\hline 31 & Fukuoka & unknown & Coastal & 9 \\
\hline 32 & Fukuoka & 2019, June & Coastal & 8 \\
\hline 33 & Chiba & 1990, December & Coastal & 11 \\
\hline 34 & Chiba & 2006, April & Coastal & 14 \\
\hline 35 & Fukui & 2020, November & Coastal & 17 \\
\hline
\end{tabular}

of each primer, $2 \mu \mathrm{L}$ buffer, and $1 \mathrm{U}$ of Ex Taq polymerase (TaKaRa, Shiga, Japan). The thermal cycling conditions involved an initial denaturation step at $94^{\circ} \mathrm{C}$ for $5 \mathrm{~min}, 45 \mathrm{cycles}$ of denaturation at $95^{\circ} \mathrm{C}$ for $10 \mathrm{~s}$, annealing at $57^{\circ} \mathrm{C}$ for $30 \mathrm{~s}$, elongation at $72^{\circ} \mathrm{C}$ for $60 \mathrm{~s}$, and final elongation at $72^{\circ} \mathrm{C}$ for $2 \mathrm{~min}$. The PCR products were confirmed by $2 \%$ agarose gel electrophoresis and purified using Nucleo Spin Gel and PCR Clean-up kit (MACHEREY-NAGEL). The purified product was eluted with $20 \mu \mathrm{L}$ elution buffer. All the amplified fragments were sequenced twice with both forward and reverse primers.

\subsection{Sequencing and Population Genetic Analyses}

The PCR products were used as the template for the 10- $\mu \mathrm{L}$ cycle sequencing reactions using BigDye Terminator v3.1 Cycle Sequencing Kit (Applied Biosystems, Foster City, CA, USA). The sequences were generated using a four-capillary 


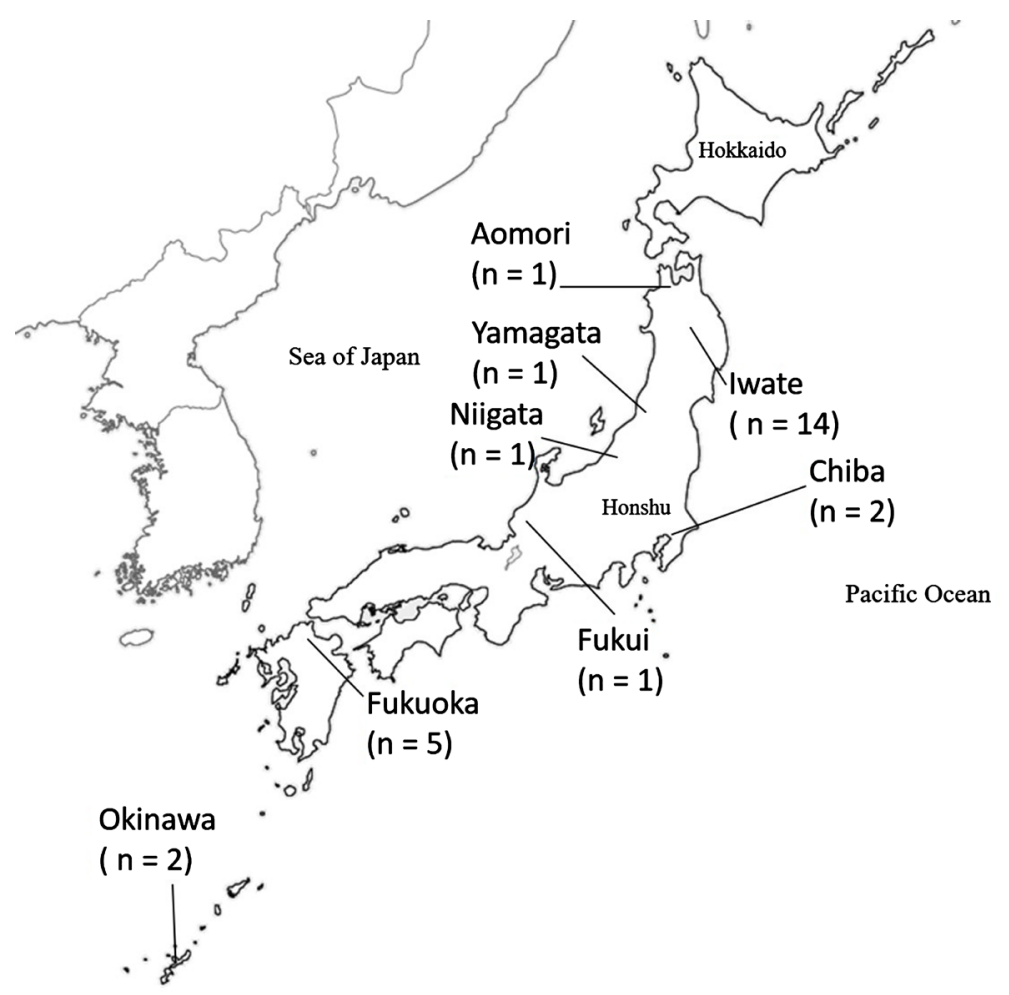

Figure 1. Map of Japan showing the locations where feather samples were collected.

3500 Genetic Analyzer (Applied Biosystems). In addition to the amplification primers, the Pah-cytb-F2-14311 (5'-TCCCTAAAAGACATCCTAGG-3') and PahCR-R2-15360 (5'-GAATGGTCCTGAAGCTAGTA-3') primers were also used for sequencing. Multiple sequence alignment was then performed using CLUSTAL $\mathrm{W}$ [25]. Haplotype and nucleotide diversities were calculated based on the 2308bp fragment of the mtDNA using DnaSP version 6.12 [26]. The haplotype network was constructed using TCS 1.21 [27]. The mtDNA sequences were deposited in the DNA Data Bank of Japan (DDBJ), European Molecular Biology Laboratory (EMBL), and GenBank under the accession numbers, LC598772LC598789.

Mismatch distribution analysis [28] was performed with DnaSP 6 and Arlequin 3.5 [29] to test for signatures of recent population expansion. DnaSP 6 was used to develop figures and Arlequin 3.5 was used to calculate the values. Tajima's D [30] and Fu's Fs test [31] of selective neutrality were performed using Arlequin 3.5. Negative Tajima's D values suggest that a population has recently increased in size. The fit to a sudden expansion model was judged using the value of the sum of squared deviations (SSD). The lack of significant differences in the SSD values indicated that the population assumed an expansion model. The Harpending's raggedness index ( $\mathrm{rg}$ ) was used to distinguish between expanded and stationary populations with the observed mismatched distributions [32]. The value of $\mathrm{rg}$ is typically low and inconsequential in expanding populations but high and significant in stationary populations [33]. The phylogenetic relationships among the sequences were traced through the maximum likelihood 
(ML) method [34] with MEGA 7 software [35]. The ML analysis was performed using the GTR + I + G model. The phylogenetic tree model was selected with the highest parameter of maximum likelihood fits using the Find Best-Fit Substitution Model of MEGA 7. An Eastern Osprey (Pandion cristatus) from Australia already registered in the database was used as the outgroup (DDBJ/EMBL/NCBI Accession number: DQ780884). Those corresponding mtDNA sequence was aligned for the phylogenetic analysis.

\section{Results}

In this study, a total of $2308 \mathrm{bp}$ of the mtDNA (1111 bp of the cyt b gene, $69 \mathrm{bp}$ of the tRNA-Thr and $1128 \mathrm{bp}$ of the CR) of 27 individuals were determined. In the cyt $b$ gene, three SNPs were confirmed, all of which were synonymous substitutions (Table 2). No mutation was confirmed in the tRNA-Thr. In the CR, 13

Table 2. Variable sites of 18 haplotypes in Japanese Osprey.

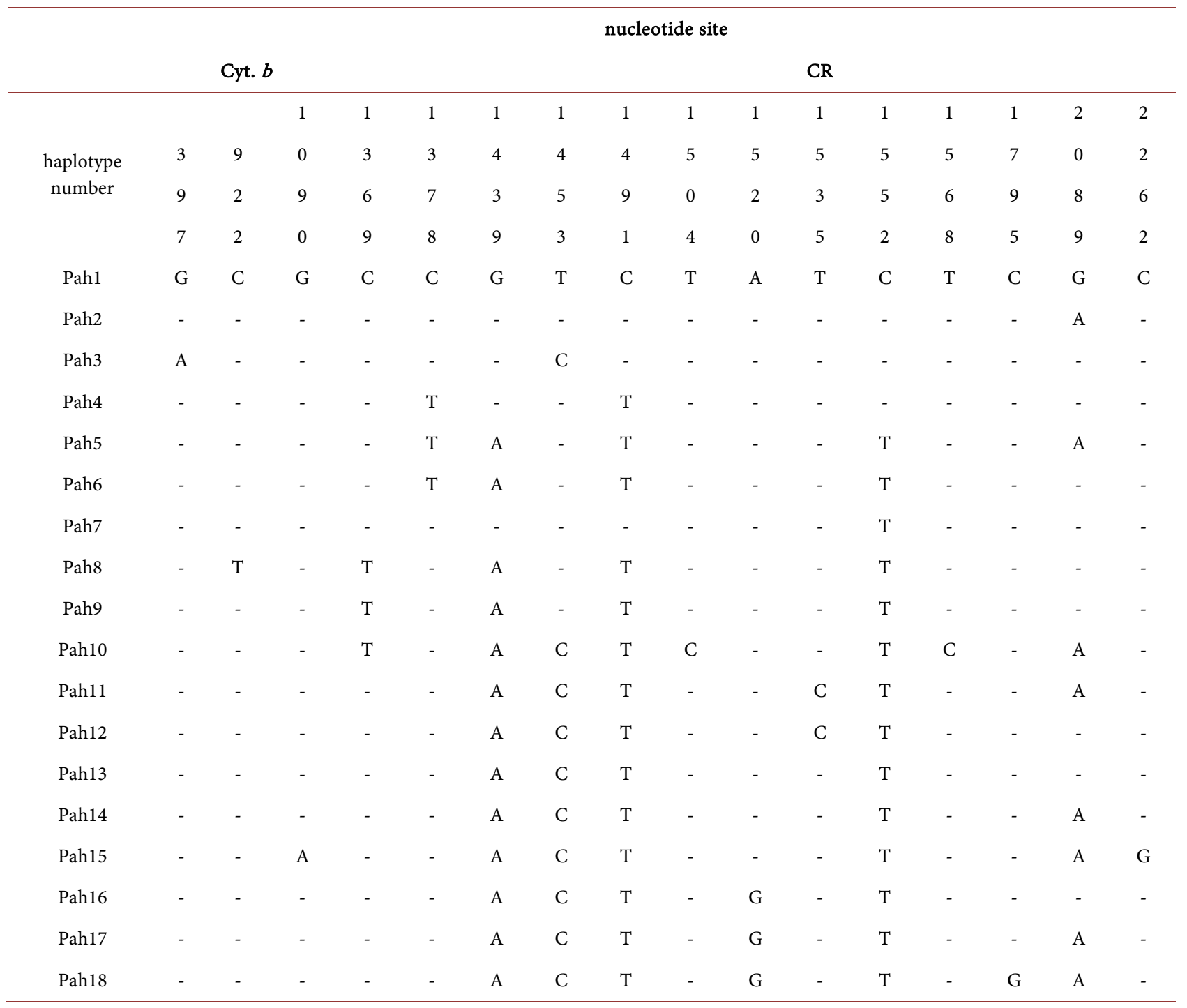

Bar indicate identity with the top sequence (haplotype Pah1). 
base substitution sites were confirmed in $1128 \mathrm{bp}$, two were transversions and the others were all transitions, nor indel was confirmed. Among the samples of Japan, eighteen haplotypes were detected in 27 individuals (Table 3). The major haplotype was Pah17, which occurred in four individuals. Pah1 and Pah14 were subsequently detected 3 individuals, Pah2 and Pah11 were detected in 2 individuals, respectively. Pah14 and Pah17 confirmed to be shared in three regions. In Iwate, Pah1 was shown to be a major haplotype and seven haplotypes were unique haplotypes. The samples from Aomori, Yamagata, Fukui and Fukuoka did not have any shared haplotypes and appeared to be composed of regional haplotypes.

Phylogenetic analysis grouped all haplotypes of Osprey into one cluster with low bootstrap values (Figure 2). Haplotype network analysis produced an extended star-shape, with focus on Pah15, and a long difference separating the center and terminal haplotypes (Figure 3 ).

The total haplotype diversity (Hd) of Osprey was $0.96 \pm 0.021$, and the nucleotide diversity $(\pi)$ was 0.00166 (Table 4 ). The Hd values of the sampled subpopulations in Iwate and Fukuoka were $0.952 \pm 0.04$ and $1.0 \pm 0.126$, respectively. The inland population of Iwate had an $\mathrm{Hd}$ of $0.939 \pm 0.058$. The mismatch distribution analysis for Osprey showed a multimodal shape (Figure 4). Both SSD and rg values were not significantly different, indicating that the Japanese Osprey did not deviate from the population expansion model. In the selective neutrality test, Tajima's D and Fu's Fs values were both negative with significant differences.

\section{Discussion}

Our findings indicate that the genetic diversity of the Japanese Osprey is relatively high compared to that of other studied raptors, such as Japanese Sparrowhawks, Eastern Buzzard, Grey-faced Buzzard, Eastern Marsh Harrier, and

Table 3. Number of Osprey haplotypes detected at various sites of Japan.

\begin{tabular}{|c|c|c|c|c|c|c|c|c|c|c|c|c|c|c|c|c|c|c|}
\hline Location & 䄏 & సี & $\frac{m}{\frac{m}{0}}$ & 売 & 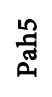 & 㺃 & 今ే & 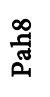 & ڤ్ & 옳 & $\begin{array}{l}\vec{F} \\
\text { [ే }\end{array}$ & 胥 & 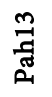 & 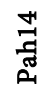 & 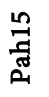 & 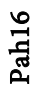 & 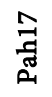 & 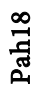 \\
\hline Iwate & 3 & 2 & 1 & & 1 & & & & & & 1 & & & 1 & 1 & 1 & 2 & 1 \\
\hline Aomori & & & & & & & 1 & & & & & & & & & & & \\
\hline Yamagata & & & & 1 & & & & & & & & & & & & & & \\
\hline Niigata & & & & & & & & & & & & & & 1 & & & & \\
\hline Chiba & & & & & & & & & & & 1 & & & 1 & & & & \\
\hline Fukui & & & & & & & & & & & & & & & & & 1 & \\
\hline Fukuoka & & & & & & 1 & & 1 & 1 & & & 1 & 1 & & & & & \\
\hline Okinawa & & & & & & & & & & 1 & & & & & & & 1 & \\
\hline Total (27) & 3 & 2 & 1 & 1 & 1 & 1 & 1 & 1 & 1 & 1 & 2 & 1 & 1 & 3 & 1 & 1 & 4 & 1 \\
\hline
\end{tabular}

The number in parenthesis represents the number of samples. Column indicates haplotype ID number. 


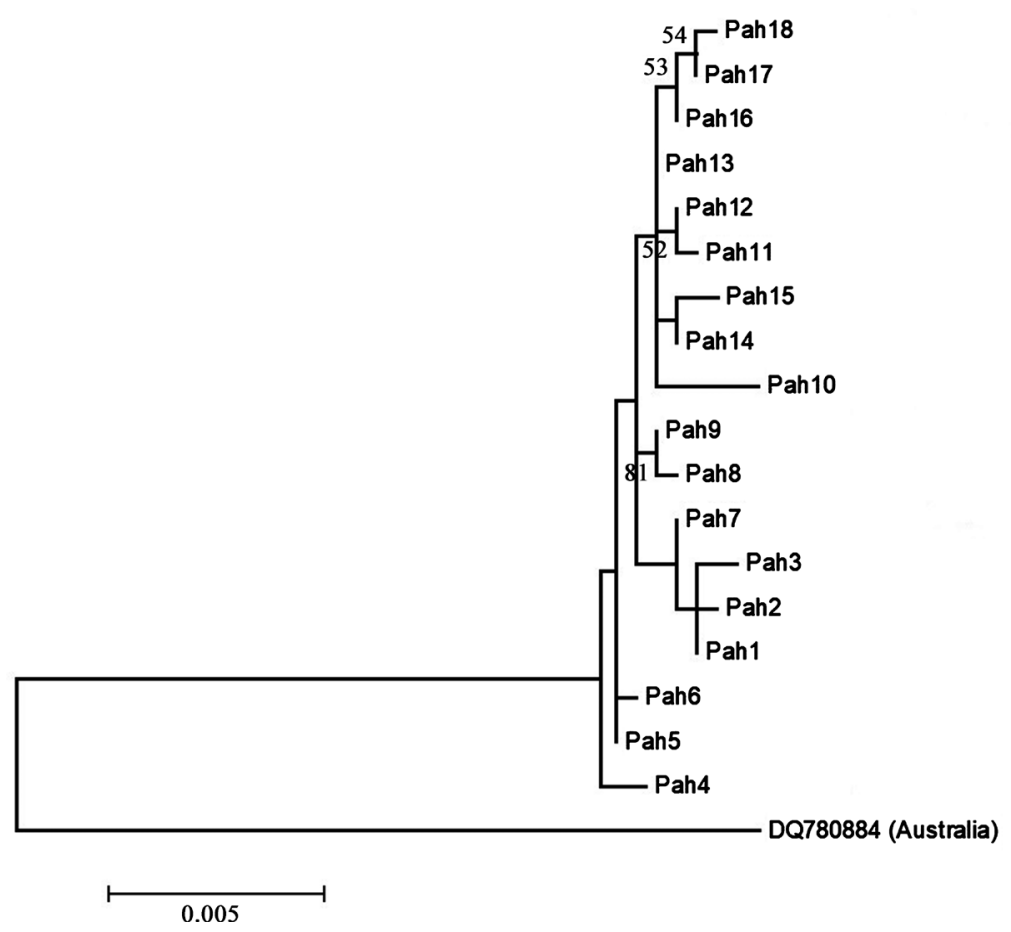

Figure 2. Phylogenetic tree constructed with the haplotypes of the Japanese Osprey using the ML method. Bootstrap values were calculated from 1000 replicates and are indicated at the branches $(>50 \%)$.

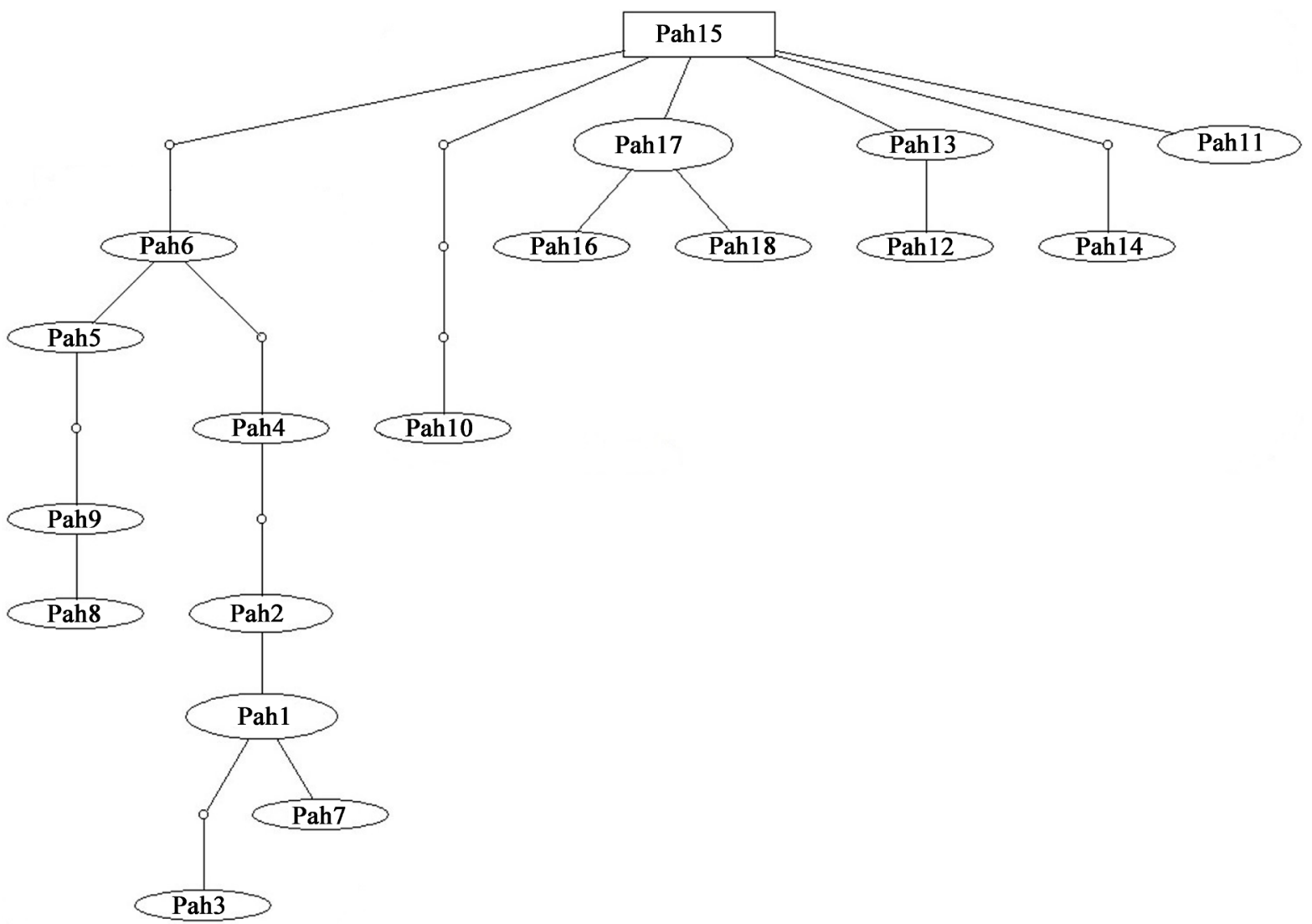

Figure 3. TCS network tree of three haplotypes among the Japanese Osprey. The numbers in the center of the circles or square represent the haplotype ID number. 
Table 4. Genetic diversity and neutrality test value of Osprey.

\begin{tabular}{ccccccccccc}
\hline & $\mathbf{n}$ & bp & $\begin{array}{c}\text { haplotype } \\
\text { number }\end{array}$ & Hd & $\pi$ & S & Tajima's D & Fu's Fs & SSD & rg \\
\hline Total & 27 & 2266 & 18 & $0.96 \pm 0.021$ & 0.00166 & 19 & $-2.1362^{\star}$ & $-5.73485^{*}$ & 0.012 & 0.026 \\
Iwate & 14 & 2266 & 11 & $0.952 \pm 0.04$ & 0.00196 & 14 & 0.20964 & $-3.73768^{\star}$ & 0.035 & 0.06 \\
Iwate (Inland) & 12 & 2266 & 9 & $0.939 \pm 0.058$ & 0.00193 & 12 & 0.508 & -2.582 & 0.041 & 0.07 \\
Fukuoka & 5 & 2266 & 5 & $1 \pm 0.126$ & 0.00194 & 9 & -0.5264 & -1.55426 & 0.079 & 0.28 \\
\hline
\end{tabular}

${ }^{*}$ Indicates $\mathrm{P}<0.05$.

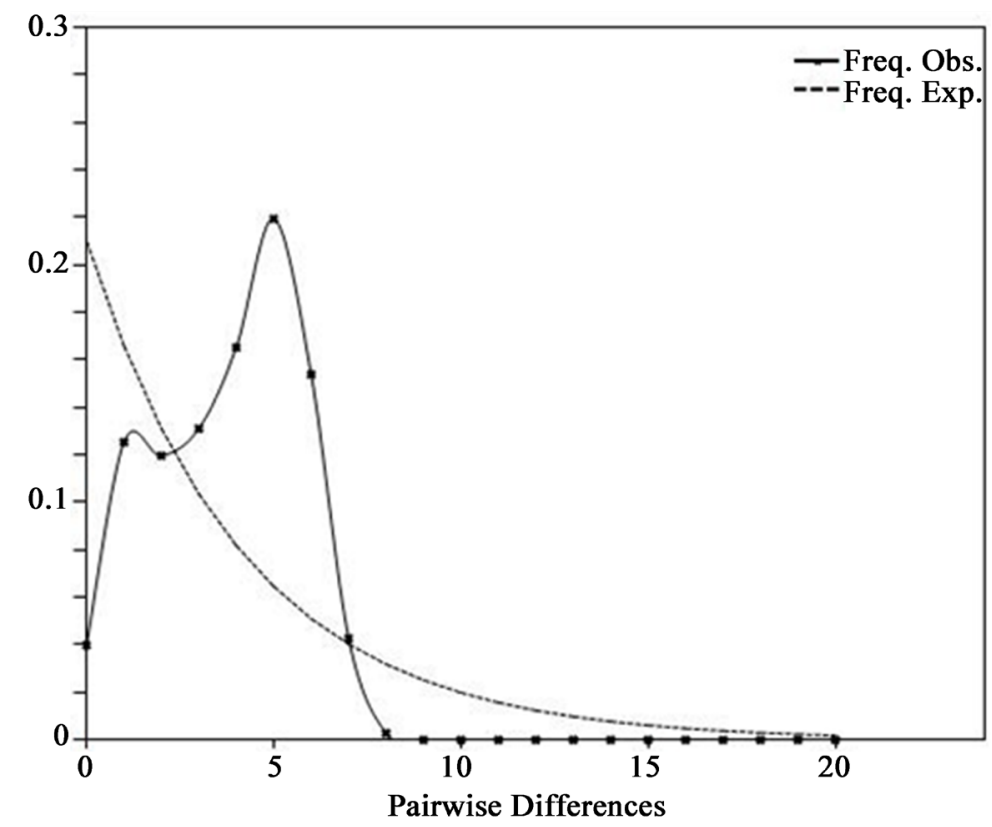

Figure 4. Mismatch distribution of all haplotypes among Japanese Osprey.

Table 5. Genetic diversity in the mtDNA, as reported in studies published for other raptor species in Japan.

\begin{tabular}{cccccc}
\hline Species $(\mathrm{n}=$ sample size) & bp & $\begin{array}{c}\text { Haplotype } \\
\text { number }\end{array}$ & $\begin{array}{c}\text { Haplotype } \\
\text { diversity }\end{array}$ & $\begin{array}{c}\text { Nucleotide } \\
\text { diversity }\end{array}$ & Reference \\
\hline Accipiter gularis $(\mathrm{n}=30)$ & 761 & 11 & 0.905 & 0.0058 & {$[39]$} \\
Buteo japonicus japonicus $(\mathrm{n}=33)$ & 1526 & 24 & 0.978 & 0.0341 & {$[38]$} \\
Buteo japonicus toyoshimai $(\mathrm{n}=12)$ & 1526 & 3 & 0.318 & 0.00022 & {$[38]$} \\
Butastur indicus $(\mathrm{n}=107)$ & 555 & 26 & 0.84 & 0.0034 & {$[37]$} \\
Circus spilonotus $(\mathrm{n}=41)$ & 1142 & 9 & 0.778 & 0.00137 & {$[40]$} \\
Pandion Haliaetus $(\mathrm{n}=27)$ & 2266 & 18 & 0.96 & 0.00166 & This study \\
Spizaetus nipalensis $(\mathrm{n}=174)$ & 418 & 22 & 0.913 & 0.71 & {$[36]$} \\
\hline
\end{tabular}

Mountain Hawk-eagle (Table 5). In inland population in Iwate, Hd was 0.939, almost as high as the overall value. It showed that the high level of genetic diversity even within a small area of the same prefecture supports the high level of genetic diversity in Japanese Osprey. It was also found that the genetic diversity 
of the inland population was sufficiently high. Thus, a sufficient number of maternal lineages seem to have been maintained within the population of Japanese Osprey. The high genetic diversity of inland areas is probably due in part to the high mobility of ospreys; although there are no reports of precise tracking of migration dispersal using GPS tracking, etc., there are reports of migration of about $1580 \mathrm{~km}$ by sign observation of chicks after they leave the nest [41]. It can be inferred that genetic diversity has been enhanced by the migration of individuals from nests in various regions to inland areas for breeding. Since Japanese Osprey is designated as NT, maintaining a high level of high genetic diversity is desirable for the protection of Japanese Osprey.

This study further revealed the genetic structure of Japanese Osprey. Pah11, 14, and 17 were shared by multiple individuals, indicating that Osprey dispersal is random, easily dispersible, and not restricted to breeding sites. In Okinawa, Osprey are not found during the breeding season, but only during the wintering season [13]. The major haplotype, Pah17, was shared between Iwate, Fukui and the wintering site of Okinawa, and the unique haplotype, Pah10, was detected only in Okinawa, indicating that Okinawa is one of the major wintering sites of Osprey. As the Japanese Osprey is increasing in abundance near inland dam lakes, we compared inland and coastal individuals, both had several region-specific haplotypes (Table 1). Although the oldest sample used in this study was 20 years old, it is not a particularly special unique sequence, and is one of the haplotypes that make up the current genetic structure of Osprey, so the storage time does not seem to have affected the results. Pah14, a haplotype detected in inland and coastal areas like Pah17, was detected in inland Iwate and coastal Niigata and Chiba, indicating that their movement is not concentrated in inland and coastal areas and the individuals are genetically dispersed. If breeding areas are unrestricted and migration is random, there is likely to be no genetic differentiation because of gene flow in and out between inland and coastal populations. However, since Osprey is a partial migration bird and it is not known which regional population are migratory or resident, analysis with a larger sample size will lead to the elucidation of migration and breeding behavior of the Osprey. Phylogenetic analysis showed low bootstrap values and no indication of genetic differentiation, indicating that the Japanese Osprey population is monophyletic. Network analysis showed large star shapes and, as in the phylogenetic analysis, no major genetic differentiation was identified. From the results of this study, it was difficult to obtain the results of multiple invasions, as shown by Monti et al. In order to show this, it would be necessary to examine other gene regions, such as ND2, using a larger number of samples. Considering the significant negative values of Tajima's D and Fu's Fs, and the non-significant SSD and rg values, Osprey in Japan is considered to be a population expansion model. Network analysis shows that Osprey haplotypes differ by up to $13 \mathrm{bp}$ as extended star-shape. Also, Mismatch distribution analysis revealed a multimodal shape. These facts indicate that Osprey in Japan has a long-term population stability. In other 
words, it is inferred that Osprey in Japan has been a long-term population stability since it experienced population expansion in the past.

The results of this study should be interpreted with some caution because, although we tried to avoid double sampling, the possibility that it occurred cannot be ignored. Implementation of microsatellite genotyping analysis would have helped identify individuals and avoid double sampling. In addition, future studies using genotyping will be necessary not only for the purpose of avoiding double sampling, but also for a more detailed interpretation of DNA analysis. It has been reported that the osprey population in the U.S. is recovering as a result of improvements in the nesting environment and water quality, so it is thought that improving the nesting environment and eliminating water pollution will also be effective in protecting the osprey population in Japan [42]. This may be the same reason why osprey populations are increasing around inland dam lakes in Japan. Dam lake, which is a large water stagnation area with improved water quality, is a good hunting ground for Osprey, and artificial release of large fish such as largemouth bass and crucian carp on the surface of the lake is also used as a good food for Osprey. At the very least, improving habitat and water pollution is considered essential for the protection of osprey.

\section{Conclusion}

We sequenced the $2308 \mathrm{bp}$ of mtDNA fragment in 27 individuals of Osprey in Japan. As a result, 18 haplotypes were detected, indicating a sufficiently high level of genetic diversity. Also, the results of network analysis, selective neutrality test, and mismatch distribution analysis indicate that Japanese Osprey is a population expansion model. Comparison of haplotypes detected in inland and coastal individuals did not detect any specific differences, suggesting that they have gene flow. Our results may be useful for future osprey conservation efforts.

\section{Acknowledgements}

We thank to Nakahara T, Deguchi S, Hirata K, Iseki F, Mori K, Sato K and Osafune $\mathrm{Y}$ for the sampling collection. The authors also thank the anonymous reviewers and editor for their expert criticism and valuable suggestions. This study was supported, in part, by Grant-in-Aid for Scientific Research C Grant Number 19k06084.

\section{Conflicts of Interest}

The authors declare no conflicts of interest regarding the publication of this paper.

\section{References}

[1] Green, R. (1976) Breeding Behaviour of Ospreys Pandion haliaetus in Scotland. Ibis, 118, 475-490. https://doi.org/10.1111/j.1474-919X.1976.tb03513.x

[2] Brazil, M. (1991) The Birds of Japan. Christopher Helm, London. 
[3] Brazil, M. (2009) Birds of East Asia. Princeton University Press, Princeton.

[4] Francour, P. and Thibault, J.C. (1996) The Diet of Breeding Osprey Pandion haliaetus on Corsica: Exploitation of Coastal Marine Environment. Bird Study, 43, 129-133. https://doi.org/10.1080/00063659609461004

[5] Shoji, A., Sugiyama, A. and Brazil, M.A. (2011) The Status and Breeding Biology of Ospreys in Hokkaido, Japan. The Condor, 113, 762-767. https://doi.org/10.1525/cond.2011.110041

[6] Lerner, H.R.L. and Mindell, D.P. (2005) Phylogeny of Eagles, Old World Vultures, and Other Accipitridae Based on Nuclear and Mitochondrial DNA. Molecular Phylogenetics and Evolution, 37, 327-346. https://doi.org/10.1016/j.ympev.2005.04.010

[7] Griffiths, C.S., Barrowclough, G.F., Groth, J.G. and Mertz, L.A. (2007) Phylogeny, Diversity, and Classification of the Accipitridae Based on DNA Sequences of the RAG-1 Exon. Journal of Avian Biology, 38, 587-602.

[8] The Ornithological society of Japan (2012) Check-List of Japanese Birds. 7th Revised Edition, the Ornithological Society of Japan, Sanda.

[9] Gill, F. and Donsker, D. (2020) IOC World Bird List (v10.2).

[10] Monti, F., Duriez, O., Arnal, V., Dominici, J.M., Sforzi, A., Fusani, L., Gremillet, D. and Montgelard, C. (2015) Being Cosmopolitan: Evolutionary History and Phylogeography of a Specialized Raptor, the Osprey Pandion haliaetus. BMC Evolutionary Biology, 15, Article No. 255. https://doi.org/10.1186/s12862-015-0535-6

[11] Ministry of the Environment (2012) How to Proceed with the Protection of Raptors. Japan Ministry of the Environment, Tokyo. (In Japanese)

[12] Ministry of the Environment (2014) Red Data Book: Threatened Wildlife of Japan. Vol. 2, Aves Gyosei, Tokyo. (in Japanese)

[13] Morioka, T., Kanouchi, T., Kawata., T. and Yamagata, N. (1995) The Birds of Prey in Japan. Bun-ichi Sogo Shuppan, Tokyo. (In Japanese)

[14] Poole, A.F. (1989) Ospreys: A Natural and Unnatural History. Cambridge University Press, New York.

[15] Kawaguchi, S. (2004) Nest Sites of the Osprey Pandion haliaetus in the Eastern Part of Kagawa Prefecture, Japan. Japanese Journal of Ornithology, 53, 36-39. https://doi.org/10.3838/jjo.53.36

[16] Yamazaki, T. (2000) Raptor Conservation and Its Relationship to the Biodiversity Conservation of Environment. Landscape Research, 64, 311-314. (in Japanese) https://doi.org/10.5632/jila.64.310

[17] Kimura, H., Abe, Y., Yanbe, E. and Ogasawara, K. (2007) Inducement of a Pair of Ospreys Pandion haliaetus to Utilize an Artificial Nest. Journal of the Yamashina Institute for Ornithology, 39, 31-34. (In Japanese) https://doi.org/10.3312/jyio.39.31

[18] Ministry of Land, Infrastructure, Transport and Tourism (2017) A Review of the Results of the Past Census of River Waterfront. Ministry of Land, Infrastructure, Transport and Tourism, Tokyo. (In Japanese)

[19] Sakakibara, T., Noguchi, M., Yoshii, C. and Azuma, A. (2020) Diet of the Osprey, Pandion haliaetus, in Inland Japan. Ornithological Science, 19, 81-86. https://doi.org/10.2326/osj.19.81

[20] Mori, K., Sakakibara, T., Noguchi, M., Yoshii, C. and Azuma, A. (2020) Food Habits of Ospreys during Brood Rearing in Coastal Areas of Iwate Prefecture, Japan. Bird Research, 16, A15-A24.

[21] Avise, J.C., Arnold, J., Ball, R.M., Bermingham, E., Lamb, T., Neigel, J.E., et al. 
(1987) Intraspecific Phylogeography: The Mitochondrial DNA Bridge between Population Genetics and Systematics. Annual Review of Ecology and Systematics, 18, 489-522. https://doi.org/10.1146/annurev.es.18.110187.002421

[22] Nagata, J., Masuda, R., Kaji, K., Kaneko, M. and Yoshida, M.C. (1998) Genetic Variation and Population Structure of the Japanese Sika Deer (Cervus nippon) in Hokkaido Island Based on Mitochondrial D-Loop Sequences. Molecular Ecology, 7, 871-877. https://doi.org/10.1046/j.1365-294x.1998.00404.x

[23] Avise, J.C. (2000) Phylogeography: The History and Formation of Species. Harvard University Press, Cambridge. https://doi.org/10.2307/j.ctv1nzfgj7

[24] Nagai, K., Takahashi, Y., Tokita, K., Uchida, K., Anzai, T. and Nakayama, F. (2020) Genetic Diversity in Japanese Populations of the Eurasian Collared Dove. Avian Research, 11, Article No. 21. https://doi.org/10.1186/s40657-020-00207-8

[25] Thompson, J.D., Higgins, D.G. and Gibson, T.J. (1994) CLUSTAL W: Improving the Sensitivity of Progressive Multiple Sequence Alignment through Sequence Weighting, Position-Specific Gap Penalties and Weight Matrix Choice. Nucleic Acids Research, 22, 4673-4680. https://doi.org/10.1093/nar/22.22.4673

[26] Rozas, J., Ferrer-Mata, A., Sánchez-DelBarrio, J.C., Guirao-Rico, S., Librado, P. and Ramos-Onsins, S.E. (2017) DnaSP 6: DNA Sequence Polymorphism Analysis of Large Datasets. Molecular Biology and Evolution, 34, 3299-3302. https://doi.org/10.1093/molbev/msx248

[27] Clement, M.D., Posada, D. and Crandall, K.A. (2000) TCS: A Computer Program to Estimate Gene Genealogies. Molecular Ecology, 9, 1657-1659. https://doi.org/10.1046/j.1365-294x.2000.01020.x

[28] Rogers, A.R. and Harpending, H. (1998) Population Growth Waves in the Distribution of Pairwise Genetic Differences. Molecular Biology and Evolution, 9, 552-569. https://doi.org/10.1093/oxfordjournals.molbev.a040727

[29] Excoffier, L. and Lischer, H.E.L. (2010) Arlequin Suite Ver 3.5: A New Series of Programs to Perform Population Genetics Analyses under Linux and Windows. Molecular Ecology Resources, 10, 564-567. https://doi.org/10.1111/j.1755-0998.2010.02847.x

[30] Tajima, F. (1983) Evolutionary Relationship of DNA Sequences in Finite Populations. Genetics, 105, 437-460. https://doi.org/10.1093/genetics/105.2.437

[31] Fu, Y.X. (1997) Statistical Tests of Neutrality of Mutations against Population Growth, Hitchhiking and Background Selection. Genetics, 147, 915-925. https://doi.org/10.1093/genetics/147.2.915

[32] Harpending, H.C., Sherry, S.T., Rogers, A.R. and Stoneking, M. (1993) The Genetic Structure of Ancient Human Populations. Current Anthropology, 34, 483-496. https://doi.org/10.1086/204195

[33] Harpending, H.C. (1994) Signature of Ancient Population Growth in a Low-Resolution Mitochondrial DNA Mismatch Distribution. Human Biology, 66, 591-600.

[34] Yang, Z. (1994) Maximum Likelihood Phylogenetic Estimation from DNA Sequences with Variable Rates over Sites: Approximate Methods. Journal of Molecular Evolution, 39, 306-314. https://doi.org/10.1007/BF00160154

[35] Kumar, S., Stecher, G. and Tamura, K. (2016) MEGA7: Molecular Evolutionary Genetics Analysis Version 7.0 for Bigger Datasets. Molecular Biology and Evolution, 33, 1870-1874. https://doi.org/10.1093/molbev/msw054

[36] Asai, S., Yamamoto, Y. and Yamagishi, S. (2006) Genetic Diversity and Extent of Gene Flow in the Endangered Japanese Population of Hodgson's Hawk-Eagle. Spi- 
zaetus nipalensis. Bird Conservation International, 16, 113-129. https://doi.org/10.1017/S0959270906000050

[37] Nagai, K., Iseki, F. and Azuma, A. (2019) Analysis of the Genetic Diversity and Structure of the Grey-Faced Buzzard (Butastur indicus) in Japan, Based on mtDNA. Zoological Science, 36, 17-22. https://doi.org/10.2108/zs180077

[38] Nagai, K., Nakayama, F., Tokita, K. and Kawakami, K. (2019) Genetic Structure and Diversity of Two Populations of the Eastern Buzzard (Buteo japonicus japonicus and B. j. toyoshimai) in Japan. Zoological Science, 36, 471-478. https://doi.org/10.2108/zs190030

[39] Nagai, K., Manawatthana, S., Tokita, K., Nualsri, C., Pierce, A.J., Sutasha, K., Sribuarod, K., Takehara, K., Round, P.D. and Higuchi, H. (2020) Genetic Structure in Japanese and Thai Populations of the Japanese Sparrowhawk Accipiter gularis. Zoological Science, 37, 232-239. https://doi.org/10.2108/zs190104

[40] Nagai, K., Takahashi, Y., Yamazaki, S. and Azuma, A. (2018) Analysis of the Genetic Diversity and Structure of the Eastern Marsh Harrier in Japan Using Mitochondrial DNA. Journal of Ornithology, 159, 73-78.

https://doi.org/10.1007/s10336-017-1480-5

[41] Yamashina Institute for Ornithology (2011) Report on the Japanese Bird Banding Scheme for 2011. Yamashina Institute for Ornithology, Chiba, 46. (In Japanese)

[42] Houghton, L.M. and Rymon, L.M. (1997) Nesting Distribution and Population Status of U. S. Ospreys 1994. Journal of Raptor Research, 31, 44-53. 